\title{
Synchronous Determination of Copper, Iron , Nickel, Cobalt, Gold and Silver in Industrial wastewater by ICP-AES
}

\author{
Wei $u^{1, a}$, Yihanna Hu, ${ }^{1, b}$, Shuang Liu ${ }^{1, c}$, Chengying Zhou ${ }^{1, d}$ \\ ${ }^{1}$ General Research Institute for Nonferrous Metals, National Engineering Lab. of \\ Biohydrometallurgy, Beijing 100088, China \\ aquwei7017@163.com, bhyhn@grinm.com, \\ Ixx.future.8382@gmail.com, ${ }^{\mathrm{d}}$ chengyingzhou@aliyun.com
}

Keywords: ICP-AES; Industrial wastewater; Synchronous determination Introduction Abstract. A method was proposed for the determination of copper, iron, nickel, cobalt, gold and silver in industrial wastewater by ICP-AES. Working conditions of the instrument and selection of analytical spectral lines were tested and optimized. The detection limit was $0.002,0.003,0.002,0.008,0.008,0.002 \mathrm{mg} / \mathrm{L}$. The effects of inhalation rate and the spectral intensity in nitric acid, hydrochloric acid, perchloric acid and sulfuric acid solution were tested. Nitrate acid with low viscosity, low surface tension and high atomization efficiency was selected. The accuracy and precision of this method were tested, and the relative error was less than $0.8 \%$, relative standard deviation was less than 5.4\%.It was accord with national standard. It proved that the determination of Copper, iron, nickel, cobalt, gold, and silver in industrial wastewater by ICP-AES was feasible.

\section{Introduction}

Industrial wastewater was very complex and difficult to determination. The best solution for industrial pollution problems was using reasonable and feasible treatment process to achieve industrial wastewater recycling and reuse.Copper, iron, nickel, cobalt, gold and silver were the necessary index with high frequency. Therefore, it was great important to detect six elements in industrial wastewate ${ }^{[1-5]}$.Currently, the national standard methods for the determination of copper, iron, nickel, cobalt, gold and silver inindustrial wastewater were atomic absorption spectroscopy and spectrophotometry. The two methods were single element analysis, the complete detection of all elements need a longer time, and also were relatively complex ${ }^{[6]}$. In this paper, copper, iron, nickel, cobalt, gold and silver in industrial wastewater were determined synchronously. It had short analysis cycle, low detection limit, wide linear range, and the results were accurate and reliable .

\section{Experimental Set Up}

For organic free industrial wastewater, dispensed $5.00-20.00 \mathrm{~mL}$ in $100 \mathrm{~mL}$ flask, added $5 \mathrm{~mL}$ nitric acid, diluted to volume and mixed, and measured by ICP-AES directly. For organic electroplating wastewater, dispensed $5.00-20.00 \mathrm{~mL}$ in $250 \mathrm{~mL}$ beaker, added $3 \mathrm{~mL}$ nitrate acid, $2 \mathrm{~mL}$ sulfuric acid, heated on furnace, until sulfur trioxide was disappeared, wait until cooled, added a small amount of water, heated until dissolved. Added $5 \mathrm{mI}$ nitric acid, boiled, cooled and rushed to $100 \mathrm{~mL}$ flask, diluted to the mark, and measured by ICP-AES.

Apparatus and reagents. Agilent 725 inductively coupled plasma atomic emission spectroscopy (USA Agilent); Copper, iron, nickel, cobalt, gold and silver mixed standard stock solution: 1.000g/L; Copper, iron, nickel, cobalt, gold and silver mixed standard working solution: $0.100 \mathrm{~g} / \mathrm{L}$, progressively diluted before use with nitric acid $(5+95)$; Nitric acid, sulfuric acid were of analytical grade; purity of argon: $99.999 \%$.

Instrument operating parameters. Optimum working parameters as shown in Table 1.

Table1 Optimal working conditions for ICP-AES

\begin{tabular}{cccccc}
\hline $\begin{array}{c}\text { RF } \\
\text { powe } \\
\mathrm{r}[\mathrm{kw}]\end{array}$ & $\begin{array}{c}\text { Flow capacity of } \\
\text { plasma } \\
\text { gas[L/min] }\end{array}$ & $\begin{array}{c}\text { Flow capacity } \\
\text { of nebulization } \\
\text { gas[L/min] }\end{array}$ & $\begin{array}{c}\text { Flow capacity of } \\
\text { auxiliary } \\
\text { gas[L/min }]\end{array}$ & $\begin{array}{c}\text { Height of } \\
\text { observation[ } \\
\text { mm] }\end{array}$ & $\begin{array}{c}\text { Integral } \\
\text { time[s] }\end{array}$ \\
\hline 1.20 & 16.5 & 0.75 & 1.50 & 10 & 5 \\
\hline
\end{tabular}


Analytical spectral lines. Analytical spectral lines of elements as shown in Table 2.

Table2 Analytical spectral lines of elements

\begin{tabular}{ccccccc}
\hline Element & $\mathrm{Cu}$ & $\mathrm{Fe}$ & $\mathrm{Ni}$ & $\mathrm{Co}$ & $\mathrm{Au}$ & $\mathrm{Ag}$ \\
\hline $\begin{array}{c}\text { Spectral } \\
\text { line[nm] }\end{array}$ & 327.395 & 238.204 & 231.604 & 238.892 & 242.794 & 328.068 \\
\hline
\end{tabular}

\section{Results and Discussion}

Selection of RF power. For organic free samples, $0.95-1.35 \mathrm{~kW}$ was selected as RF power generrally. Since RF power would be increased as increase of emission intensity, background radiation would be enhanced as increase of RF power, ratio of signal with background would be lowed, detection limit would be increased. Therefore, RF power was proposed $1.20 \mathrm{~kW}^{[7-8]}$.

Selection of flow capacity of nebulization gas. The range of flow capacity of nebulization gas was $0-1.3 \mathrm{~L} / \mathrm{min}$. The sample was inhaled accellerate, analysis time was shorten as increasing of flow capacity of nebulization gas. However, standard fluid and use of argon would be increased, and also, accuracy of analysis was decreased. Therefore, flow capacity of nebulization was proposed $0.72 \mathrm{~L} / \mathrm{min}$. Selection of spectral lines of elements and interference of elements. Spectral intensity and interference lines were displayed on the use of ICP-AES. Mixed standard and single standard were scanned, the spectral line which had high sensitivity, lower spectral interference, higher ratio of signal with background, lower detection limit were selected. The coexisting elements in electroplating wastewater had no effect on measured elements.

Drawing of standard curve. Pipetted $1.00 \mathrm{~mL}, 5.00 \mathrm{~mL}, 10.00 \mathrm{~mL}, 50.00 \mathrm{~mL}$ mixed standard working solution in $100 \mathrm{~mL}$ flask, added $5 \mathrm{~mL}$ nitric acid, diluted to volume and mixed. The concentration of copper, iron, nickel, cobalt, gold and silver were $1.00 \mathrm{mg} / \mathrm{L}, 5.00 \mathrm{mg} / \mathrm{L}, 10.00 \mathrm{mg} / \mathrm{L}, 50.00 \mathrm{mg} / \mathrm{L}$. Measured intensity of each element, and then drawed standard curve, calculated the regression equation and correlation coefficient. The results show that copper, iron, nickel, cobalt, gold and silver concentration in the above range of linear calibration curve had good linearity, the correlation coefficients were greater than 0.9999 .

Detection limit. According to the mixed standard curve, measured blank solution for 11 times, detection limit was of three times of the standard deviation $(\mathrm{S} / \mathrm{N}=3)$ :

$0.002,0.003,0.002,0.008,0.008,0.002 \mathrm{mg} / \mathrm{L}$.

Selection of acidity. Pipetted $5.00 \mathrm{~mL} 0.100 \mathrm{~g} / \mathrm{L}$ mixed standard working solution in four $100 \mathrm{~mL}$ flask, added $5 \mathrm{~mL}$ nitric acid, hydrochloric acid, perchloric acid, sulfuric acid, diluted to the mark, shaked, measured by ICP-AES. The results showed that acid could weaken intensity of spectral lines. And strengthen the adherence of nitric acid to sulfuric acid sequence, as shown in Table 3. Therefore, nitric acid was selected for lower viscosity and surface tension, higher atomization efficiency ${ }^{[9]}$. The amount of nitric acid was tested either, the results show that intensity of spectral line would deduced by increasing of nitric acid, as shown in Table 4. Considered the concentration of nitric acid was too low will cause the hydrolysis of the metal ions, we choose $5 \%$ nitric acid.

Table 3 Selection of acid

\begin{tabular}{|c|c|c|c|c|c|c|}
\hline Kind of acid & $\begin{array}{c}\mathrm{Cu} \\
327.395 \mathrm{~nm} \\
\text { Spectral } \\
\text { intensity } \\
{[\mathrm{c} / \mathrm{s}]}\end{array}$ & $\begin{array}{c}\mathrm{Fe} \\
238.204 \\
\mathrm{~nm} \\
\text { Spectral } \\
\text { intensity } \\
{[\mathrm{c} / \mathrm{s}]}\end{array}$ & $\begin{array}{c}\mathrm{Ni} \\
231.604 \\
\mathrm{~nm} \\
\text { Spectral } \\
\text { intensity } \\
{[\mathrm{c} / \mathrm{s}]}\end{array}$ & $\begin{array}{c}\text { Co } \\
238.892 \\
\mathrm{~nm} \\
\text { Spectral } \\
\text { intensity } \\
{[\mathrm{c} / \mathrm{s}]}\end{array}$ & $\begin{array}{c}\mathrm{Au} \\
242.794 \\
\mathrm{~nm} \\
\text { Spectral } \\
\text { intensity } \\
{[\mathrm{c} / \mathrm{s}]}\end{array}$ & $\begin{array}{c}\mathrm{Ag} \\
328.068 \\
\mathrm{~nm} \\
\text { Spectral } \\
\text { intensity } \\
{[\mathrm{c} / \mathrm{s}]}\end{array}$ \\
\hline No acid & 20712.9 & 14616.0 & 1469.3 & 4564.3 & 2270.3 & 3244.6 \\
\hline Nitric acid & 20707.2 & 14601.6 & 1468.1 & 4563.0 & 2266.4 & 3239.1 \\
\hline $\begin{array}{l}\text { Hydrochloric } \\
\text { acid }\end{array}$ & 20658.0 & 14567.7 & 1456.8 & 4559.9 & 2254.1 & 3228.7 \\
\hline $\begin{array}{l}\text { Perchloric } \\
\text { acid }\end{array}$ & 20655.6 & 14548.9 & 1439.4 & 4545.5 & 2243.6 & 3229.3 \\
\hline Sulfuric acid & 20332.7 & 13987.1 & 1398.7 & 4466.0 & 2238.1 & 3057.9 \\
\hline
\end{tabular}


Table 4 Selection of acidity

\begin{tabular}{|c|c|c|c|c|c|c|}
\hline $\begin{array}{c}\text { Concentration } \\
\text { of Nitric acid } \\
\%\end{array}$ & $\begin{array}{c}\mathrm{Cu} \\
\text { 327.395nm } \\
\text { Spectral } \\
\text { intensity } \\
{[\mathrm{c} / \mathrm{s}]}\end{array}$ & $\begin{array}{c}\mathrm{Fe} \\
238.204 \\
\mathrm{~nm} \\
\text { Spectral } \\
\text { intensity } \\
{[\mathrm{c} / \mathrm{s}]}\end{array}$ & $\begin{array}{c}\mathrm{Ni} \\
231.604 \\
\mathrm{~nm} \\
\text { Spectral } \\
\text { intensity } \\
{[\mathrm{c} / \mathrm{s}]} \\
\end{array}$ & $\begin{array}{c}\text { Co } \\
238.892 \\
\text { nm } \\
\text { Spectral } \\
\text { intensity } \\
{[\mathrm{c} / \mathrm{s}]} \\
\end{array}$ & $\begin{array}{c}\mathrm{Au} \\
242.794 \\
\mathrm{~nm} \\
\text { Spectral } \\
\text { intensity } \\
\text { [c/s] }\end{array}$ & $\begin{array}{c}\mathrm{Ag} \\
328.068 \\
\mathrm{~nm} \\
\text { Spectral } \\
\text { intensity } \\
{[\mathrm{c} / \mathrm{s}]} \\
\end{array}$ \\
\hline 3.0 & 20776.3 & 14613.8 & 1470.5 & 4566.9 & 2275.9 & 3300.7 \\
\hline 5.0 & 20707.2 & 14601.6 & 1468.1 & 4563.0 & 2266.4 & 3239.1 \\
\hline 7.0 & 20605.9 & 14799.1 & 1477.4 & 4557.1 & 2258.1 & 3234.8 \\
\hline 10.0 & 20411.0 & 14653.8 & 1461.8 & 4521.9 & 2239.6 & 3230.7 \\
\hline
\end{tabular}

Accuracy and precision. Accordance to the test method, precision was tested with one of samples. The relative standard deviations within $0.8 \%$, in line with the national standard limit values, as shown in Table 5.Five kinds of samples were measured by proposed method and atomic absorption spectrometry, the relative error of measurement results within 5.4\%, in line with the national standard limit values, as shown in Table 6.

Table 5 Precesion test

\begin{tabular}{cccc}
\hline Element & $\begin{array}{c}\text { Results of proposed method }(\mathrm{n}=6) \\
{[\mathrm{mg} / \mathrm{L}]}\end{array}$ & $\begin{array}{c}\text { Average } \\
{[\mathrm{mg} / \mathrm{L}]}\end{array}$ & $\begin{array}{c}\text { RSD } \\
{[\%]}\end{array}$ \\
\hline $\mathrm{Cu}$ & $17.15,17.17,17.19,17.08,17.10,17.16$ & 17.14 & 0.3 \\
\hline $\mathrm{Fe}$ & $648.3,650.0,648.7,647.9,651.2,648.7$ & 649.1 & 0.2 \\
\hline $\mathrm{Ni}$ & $12.39,12.35,12.35,12.40,12.43,12.38$ & 12.38 & 0.3 \\
\hline $\mathrm{Co}$ & $5.41,5.40,5.44,5.38,5.41,5.41,5.34$ & 5.40 & 0.6 \\
\hline $\mathrm{Au}$ & $3.69,3.69,3.62,3.65,3.67,3.66$ & 3.66 & 0.8 \\
\hline $\mathrm{Ag}$ & $40.60,40.50,40.58,40.53,40.53,40.28$ & 40.50 & 0.3 \\
\hline
\end{tabular}

Table 6 Contrast for samples

Results of proposed method $(n=6)$

$[\mathrm{mg} / \mathrm{L}]$

\begin{tabular}{|c|c|c|c|c|c|c|c|c|c|}
\hline \multirow{3}{*}{ Element } & \multicolumn{9}{|c|}{$[\mathrm{mg} / \mathrm{L}]$} \\
\hline & \multicolumn{3}{|c|}{$\mathrm{Cu}$} & \multicolumn{3}{|c|}{$\mathrm{Fe}$} & \multicolumn{3}{|c|}{$\mathrm{Ni}$} \\
\hline & ICP-AES & AAS & $\operatorname{Er}[\%]$ & ICP-AES & AAS & $\operatorname{Er}[\%]$ & ICP-AES & VS & $\operatorname{Er}[\%]$ \\
\hline $1 \#$ & 17.15 & 17.11 & 0.3 & 648.3 & 644.2 & 0.7 & 12.39 & 12.33 & 0.5 \\
\hline $2 \#$ & 14.11 & 14.08 & 0.2 & 589.6 & 595.1 & 1.0 & 11.59 & 11.62 & 0.3 \\
\hline $3 \#$ & 10.86 & 10.92 & 0.6 & 603.5 & 602.9 & 0.1 & 12.67 & 12.67 & 0 \\
\hline $4 \#$ & 12.56 & 12.55 & 0.8 & 656.8 & 646.0 & 1.7 & 10.47 & 10.50 & 0.3 \\
\hline $5 \#$ & 16.72 & 16.79 & 0.5 & 611.2 & 611.9 & 0.1 & 11.47 & 11.44 & 0.3 \\
\hline
\end{tabular}

Results of proposed method $(\mathrm{n}=6)$

$[\mathrm{mg} / \mathrm{L}]$

\begin{tabular}{cccccccccc} 
Element & \multicolumn{3}{c}{ Co } & \multicolumn{3}{c}{$\mathrm{Au}$} & \multicolumn{3}{c}{ Ag } \\
\cline { 2 - 10 } & ICP-AES & VS & Er[\%] & ICP-AES & AAS & Er[\%] & ICP-AES & AAS & Er[\%] \\
\hline $1 \#$ & 5.41 & 5.40 & 0.2 & 3.69 & 3.59 & 2.8 & 40.60 & 40.58 & 0.1 \\
\hline $2 \#$ & 2.68 & 2.68 & 0 & 1.16 & 1.15 & 0.9 & 15.98 & 16.07 & 0.6 \\
\hline $3 \#$ & 1.96 & 1.96 & 0 & 3.58 & 3.55 & 0.9 & 19.87 & 19.96 & 0.5 \\
\hline $4 \#$ & 2.11 & 2.14 & 1.5 & 6.97 & 7.06 & 1.3 & 60.05 & 60.15 & 0.2 \\
\hline $5 \#$ & 3.78 & 3.82 & 1.1 & 3.47 & 3.44 & 0.9 & 40.68 & 40.72 & 0.1 \\
\hline
\end{tabular}




\section{Conclusions}

Appropriate instrument operating parameters( RF power $1.20 \mathrm{~kW}$, flow capacity of nebulization gas 0.72L/min), Spectral lines(Cu: 327.395nm, Fe: 238.204nm, Ni: 231.604nm,Co: 238.892nm, Au: 242.794nm, Ag: $328.068 \mathrm{~nm}$ ), as well as kind and concentration of acid (5\% nitric acid) were selected. In this paper, detection limit of each element was calculated either. The concentration of copper, iron, nickel, lead, cobalt, gold and silver in industrial wastewater were synchronous determined

\section{Acknowledgment}

The author would like to thank Professor Song yongsheng and the support of "International Scientific and Technological CooperationProjects" (NO.2014DFA90920).

\section{References}

[1]WU Juan. Determination of seven elements in wastewater by ICP-AES. CHINESE JOURNAL OF HEALTH LABORATORY TECHNOLOGY. Vol.15(2005), p.316

[2]YUE Tai-xing, LI Xiao-jing, LI Hong-li et al Simultaneous Determination of Twenty Elements in Wastewater by ICP-MS with Microwave Digestion. Vol.24(2012), p.44

[3] LU Dan, RUAN Yi.ICP-AES Determination of Lead, Cadmium, Chromium and Arsenic in Industrial Waste Water [J].PTCA(PART B:CHEM. ANAL).Vol.43(2007), p.1022

[4]LI Chen,SHU Wen-bo,YANG Na-na et al.. Progress in Treatment of E|ectroplating Wastewater [J]. Electroplating \& Pollution Control.Vol.30(2010), p.40

[5]YOU Zongbao,LUO Jianping,CHEN Jianbin.Simultaneous Determination of $\mathrm{Cd} \mathrm{Cr} \mathrm{Cu} \mathrm{Ni} \mathrm{Pb}$ and Zn Contents in Waste Water by IRIS/AP-ICP-AES. Chinese Jo/rnCZ of Spectroscopy LcborCtory. Vol.17(2000), p.599

[6]LI Chen, SHU Wen-bo, YANG Na-na et al.Progress in Treatment of Electroplating Wastewater with Waste. Electroplating\&Pollution Control Vol.30(2010), p.40

LONG Jia-hong, XU Hiong-fei, KANG Xiao-yu et a1. Determination of $\mathrm{Cu}$, Ni and $\mathrm{Sn}$ in [7]Wastewater of Manufactory of Circuit Board by ICP-OES [J]. Chinese Journal of Spectroscopy Laboratory. Vol.29(2012), p.2208

[8]XIAO Xin-feng, LUO Ya-jan, WANG Zhao-li et a1. Reverse flow-injection spectrophotometric determination of chromium in electroplating waste water and sludge $[\mathrm{J}]$. Metallurgical Analysis.Vol.28(2008), p.47

[9]YANG Xiao-yan, LI Li, WANG Bi-xuan et al. Determination of Cr in electroplating waste water by ICP-AES [J]. Materials Protection. Vol. 9(2008), p.70 